\title{
Research Paper: Predicting Borderline Personality Traits in Adolescents Based on Parenting Styles and Emotion Regulation Strategies
}

\author{
Mona Etemadi ${ }^{1}$, Asma Aghebati² ${ }^{(i)}$, Fatemeh Ayatmehr ${ }^{3}$, Ahmad Ashoori $^{2 *}$ (i) \\ 1. Student Research Committee, Iran University of Medical Science, Tehran, Iran \\ 2. Department of Clinical Psychology, School of Behavioral Sciences and Mental Health (Tehran Institute of Psychiatry), Iran University of Medical \\ Science, Tehran, Iran. \\ 3. Department of Clinical Psychology, Faculty of Psychology and Education, Kharazmi University, Tehran, Iran.
}

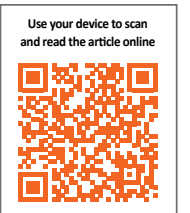

cittation: Etemadi, M., Aghebati, A., Ayatmehr, F., \& Ashoori, A. (2020). Predicting Borderline Personality Traits in Adolescents Based on Parenting Styles and Emotion Regulation Strategies. Journal of Practice in Clinical Psychology, 8(2), 133-142. https://doi.org/10.32598/jpcp.8.2.656.1

dol'https://doi.org/10.32598/jpcp.8.2.656.1

\section{(i) (9)}

\section{Article info:}

Received: 14 Dec 2018

Accepted: 25 Feb 2020

Available Online: 01 Apr 2020

\section{Keywords:}

Parenting styles, Emotion regulation strategies,

Borderline personality traits, Adolescents

\section{ABSTRACT}

Objective: The present study aimed to predict borderline personality traits in adolescents based on parenting styles and emotion regulation strategies.

Methods: This research was a cross-sectional study. The statistical population included all female high school students in Sanandaj City, Iran in the academic year 2016-17. Out of them, a total of 261 students were selected as the study sample using a random multistage cluster sampling method. The following instruments were used to gather the study data: the schizotypal trait questionnaire- $\mathrm{B}$, the emotion regulation questionnaire, and the parenting styles inventory. The study data were analyzed using multiple regression analysis and the Pearson correlation coefficient.

Results: According to the findings, authoritarian and authoritative parenting styles significantly predicted borderline personality total score and its components $(\mathrm{P}<0.01)$. But, in this model, permissive parenting was not a significant predictor $(\mathrm{P}>0.01)$. In addition, the results indicated that both emotion regulation strategies of reappraisal and suppression significantly predicted borderline personality total score and its components $(\mathrm{P}<0.05)$.

Conclusion: According to the study results, parenting styles and emotion regulation strategies could be regarded as important variables in predicting borderline personality symptoms, and they should be targeted in therapeutic interventions to reduce borderline personality symptoms.

\footnotetext{
* Corresponding Author:

Ahmad Ashuri, PhD.

Address: Department of Clinical Psychology, School of Behavioral Sciences and Mental Health (Tehran Institute of Psychiatry), Iran University of Medical Science, Tehran, Iran.

Tel: +98 (21) 66551655

E-mail:fatemeayatmehr@gmail.com
} 


\section{Highlights}

- Parenting styles and emotion regulation strategies can predict borderline personality symptoms in adolescents.

- Authoritarian parenting style has direct relation with borderline personality symptoms in adolescents.

- Authoritative parenting style has indirect relation with borderline personality symptoms in adolescents.

- Emotion regulation has an important role in predicting borderline personality traits.

- To reduce borderline personality traits in adolescents, it is necessary to training authoritative parenting style to parents and emotion management to adolescents.

\section{Plain Language Summary}

We examined the role of parenting and emotion regulation in predicting borderline personality traits and concluded that parenting, as an important environmental factor, and emotion management can anticipate borderline traits. Fortunately there are some ways to reduce symptoms of this undesirable personality pattern. For example teaching parents the best way to interact with their children and also the proper management of emotions to adolescents.

\section{Introduction}

atients with Borderline Personality Disor-

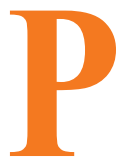
der (BPD) are on the neurosis and psychosis border. These patients always seem to be in a critical state, and mood swing is a commonly observed symptom in them (Sadock, Kaplan, \& Sadock, 2015). Although studies have shown that BPD is more prevalent among adolescents compared with adults (Torgersen, Kringlen, \& Cramer, 2001), its diagnosis is controversial in children and adolescents. The exact cause of BPD is unknown, but researchers have increasingly come to view emotional dysregulations as the core feature of BPD (Hutsebaut, Feenstra, \& Kamphuis, 2016; Hutsebaut, Kamphuis, Feenstra, Weekers, \& De Saeger, 2017). Impulsive behaviors such as aggression, self-mutilating, suicidal attempts, unprotected sex, sense of urgency, and so on may appear because of several reasons (Millon, Millon, Meagher, Grossman, \& Ramnath, 2004). One of the most important reasons is emotion dysregulation in BPD (Lotfi, Amini, Fathi, Karami, \& Ghiasi, 2014). Gross defines emotion regulation as a mechanism that influences the way people experience or express their emotions (Fletcher, Parker, Bayes, Paterson, \& McClure, 2014). In this developmental stage, adolescents frequently go through new and intense emotional experiences with peers and romantic partners that need to be regulated (Olivari, Cuccì, Bonanomi, Tagliabue, \& Confalonieri, 2018). Emotion regulation difficulties resulting from impulse management difficulties and limited access to emotion regulation strategies showed the strongest relationship with BPD (Lotfi et al., 2014; Lotfi, Amini, Fathi, Karami, Ghiasi, \& Sadeghi, 2018). A structure for organizing different emotion regulation strategies focuses on interruptions in the emotion production process (Kashdan, Barrios, Forsyth, \& Steger, 2006). This issue shows the importance of attention to emotion regulation, especially in adolescents, because their developmental condition and specific emotions during juvenility are crucial (Aliloo, Khanjani, \& Bayat, 2017). Because BPD is characterized by emotion regulation problems, improvement in emotion regulation seems to be a potential mechanism in the treatment of this disorder (Warren, 2015). Based on the theory of emotion regulation, if the individual with BPD who is healthy and adaptive can easily regulate his/her emotions, or he/she can act healthy and adaptive (Morey, 2017; Skodol et al., 2011).

On the other hand, the gene-environment interaction approach emphasizes the important role of environmental factors along with genetic and biological ones in the development of BPD. So those with BPD are born with a range of neurological and behavioral vulnerabilities that are exacerbated by environmental factors during their development (Judd \& McGlashan, 2003). Research studies have shown that those who develop BPD during adolescence, may have had negative experiences during childhood, such as abuse or lack of emotional response from their parents (Brune et al., 2015). One aspect of the parent-child relationship that may be related to BPD 
symptoms is parents' criticism of their children's emotional expression (Hooley, 2007). Therefore, parentchild relationship and parenting styles could be among the important factors in the formation and development of BPD in children and adolescents. Parenting styles are forms of parental feedback given by parents to their children (Jansen, Daniels, \& Nicholson, 2012). They are classified based on two independent dimensions of responsiveness and demandingness into three categories: authoritative, authoritarian, and permissive parenting styles (Baumrind, as cited in Besharat, Hooshmand, Rezazadeh, \& Gholamali Lavasani, 2015). Given that the previous studies have shown a unique relationship between BPD symptoms in adolescents and critical caregivers, more studies are needed to consider caregiver behaviors toward children from their middle childhood to late adolescence. We can conclude from the literature that despite the high prevalence of borderline personality traits among adolescents, especially in Iran, research studies have not paid enough attention to borderline traits in adolescents. Lotfi et al. (2014) found positive relationships between BPD and the following cognitive emotion regulation styles: Self-blame, rumination, catastrophizing, blaming others. They also found negative relationships between BPD and the following styles: acceptance and positive reappraisal. They also revealed the significant role of cognitive emotion regulation strategies in explaining BPD.

Regarding parenting styles, Lyons-Ruth, Choi-Kain, Pechtel, Bertha, \& Gunderson, (2011) found that those with BPD had received less support in their mother-child interactions. Their results indicated that perceived quality of parental support moderates the response system to stress in patients with BPD. Therefore, previous studies have shown that those with BPD are brought up in families with a high level of psychopathology and also with dysfunctional parenting styles. However, no study has ever conducted on the relationship between perceived quality of parenting and BPD symptoms in a clinical, but non-psychiatric sample. Besides, few studies have focused on the relationship between emotion regulation and key parental factors, such as emotional functioning and emotional expression (Sansone, Farukhi, \& Wiederman, 2013). Given that BPD is related to severe psychosocial problems and a high rate of mortality due to suicide (Skodol, Underson, Pfohl, Widiger, John Livesley, \& Siever, 2002), raising the risk for substance use, vulnerability to violence, and mental disorders (Baglivio, Epps, Swartz, Huq, Sheer, \& Hardt, 2014; Underwood \& Washington, 2016; Wojciechowski, 2018), it seems necessary to identify the factors predicting BPD. On the other hand, child-rearing methods are related to social problems, so that psychological and social maturity of adolescents can have significant effects on academic achievement, academic failure, social competence, behavioral problems, and drug abuse, flexibility, self-constraint, and depression in adolescence (Heaven et al., 2002). Therefore, the examination of child-rearing techniques in relation to borderline personality traits can reveal the best methods to prevent BPD. In other words, these parenting styles could be used in parents' training programs.

Despite the good theoretical and empirical background of personality trait representations, previous studies have not addressed the components of emotional difficulties in BPD. So, more cross-culturally studies are needed for patients with BPD. Given the importance of environmental factors, especially family experiences and parenting styles in the emotional development of adolescents, and considering the role of emotion regulation in the prediction of borderline personality traits, the present study aims to predict borderline personal traits in adolescents based on parenting styles and emotion regulation strategies. The present study assesses borderline personality traits in adolescents simultaneously with parenting styles applied to them, previous research has investigated the association or cause of borderline personality disorder in adults, also evaluation of parenting styles has been retrospective.

\section{Methods}

This is a cross-sectional study using multiple regression analysis. The statistical population included all female high school students (14 to 16 years old) in Sanandaj City, Iran studying in the academic year 2016-2017. The study participants were selected using a random multistage cluster sampling method. In the first step, one district was randomly selected from two districts of Sanandaj. Then, five high schools were randomly selected form that district, and in the next step, four classrooms were randomly selected from each high school in different grades. Based on the Morgan table and considering the size of the statistical population $(n=1400)$, the sample size was estimated to be 300 . Out of the selected classrooms, a total of 330 students were randomly selected. The obtained data were analyzed in SPSS V. 18.

First of all, the researcher referred to the Sanandaj Education Organization and the necessary consultations were held to obtain a letter of introduction to present to the schools.

After coordinating with the headmaster, the researcher went to the students' classrooms and gave the necessary 
explanations for the research and the non-compulsory participation. Then he distributed the questionnaires and waited in the class until the questionnaires are completed. The mothers of the students were also invited to school and asked to answer parenting questionnaires. The researcher has explained the purpose of the study and the non-compulsory participation for mothers.

The inclusion criteria were students living with parents and personal desire to participate in the study. The exclusion criteria were students with psychological, neurological, and developmental disorders and head trauma.

Based on the schizotypal trait questionnaire-B, scoring above 7 indicates borderline personality traits, and considering the mean score of the sample (9.77), we assume the sample as clinical. The clinical refers to people who have traits of borderline personality.

In this study, all participants, whether students or parents, volunteered to participate in the study. They all studied the research consent and participated in the study if they so desired. Participants were reminded that they should not participate in the research if they did not wish to cooperate. The right to opt out of the research was also explained to the subjects.

Given that both students and parents entered the research process, it was important to emphasize the principles of confidentiality, and that only the general and group results of this research would be published without mentioning the name and specifications. Also, since the purpose of this study was to predict and with the presence of a large number of samples, it is necessary to guide people who have borderline personality traits and are prone to the disorder.

Research has also been approved by the Ethics Committee of Iran University of Medical Sciences.

\section{Study instruments}

\section{The schizotypal trait questionnaire-B form (STB)}

This questionnaire was developed by Claridge and Broks (1984) at the University of Oxford, and revised by Rawlings, Claridge, and Freeman (2001). This questionnaire has two scales: one scale A: Schizotypal Personality (STA) and one scale B: Borderline Personality (STB). The Schizotypal Trait Questionnaire-B form (STB) was used in this study which measures borderline personality traits. It has 21 Yes/No items. A Yes is scored 1 and a No is scored 0 . Based on STB's scoring, scores above
7 shows borderline personality traits. The questionnaire has three factors: hopelessness, impulsivity, and dissociative and paranoid symptoms dependent on tension. Rawlings, Claridge, and Freeman (2001) reported an alpha value of 0.80 for the total scale. Shankar (1998) also confirmed the discriminant and construct validity of the STB in a study with clinical patients with BPD. In Iran, Mohammadzadeh, Goodarzi, Taghavi, and Mollazadeh (2006) reported a 4-week test-retest reliability estimates of $0.84,0.53,0.72$, and 0.50 respectively for the total scale, hopelessness, impulsivity, and dissociative and paranoid symptoms dependent on tension. The Cronbach alpha values of $0.77,0.64,0.58$, and 0.57 were found for the total scale, hopelessness, impulsivity, and dissociative and paranoid symptoms dependent on tension, respectively. The STB has also good factorial and discriminant validity estimates in Iran. In the present study, The Cronbach alpha values of $0.78,0.52,0.53$, and 0.43 were found respectively for the total scale, hopelessness, impulsivity, and dissociative and paranoid symptoms dependent on tension.

\section{The Emotion regulation Questionnaire (ERQ)}

This 10-item questionnaire was developed by Gross and John (2003) and has 2 subscales: reappraisal (6 items) and suppression (4 items). The items are rated on a 7-point Likert-type scale ranging from totally disagree (1) to totally agree (7). The Cronbach alpha values of 0.79 and 0.73 were found for reappraisal and suppression, respectively, and after three months, a Cronbach alpha of 0.69 was found for the total scale (Gross \& John, 2003). At the University of Milan, the Cronbach alpha values from 0.48 to 0.68 were found for reappraisal, and alpha values from 0.42 to 0.63 for suppression (Balzarotti, John, \& Gross, 2010). Besides, among the state employees and catholic students of the University of Milan, the Cronbach alpha values of 0.24 and -0.14 were reported for reappraisal with the positive and negative affect schedules, respectively. Also, the Cronbach alpha values of -0.15 and 0.04 were reported for suppression with the positive and negative affect schedules, respectively (Balzarotti, John, \& Gross, 2010). The Persian version of the ERQ has been validated in the Iranian culture in 2012. The reliability of the scale was assessed using the internal consistency method (the Cronbach alpha values ranging from 0.60 to 0.81 ), and its validity was assessed by the principal component analysis using varimax rotation; the correlation between the two subscales $(r=0.13)$, and the validity of the questionnaire were reported to be good. 


\section{The Parenting Styles Inventory (PSI)}

This scale, which was first developed by Diana Baumrind in 1972, contains 30 items (each of authoritarian, authoritative, and permissive parenting style consists of 10 statements). The items are rated on a 5-point Likert-type scale. Buri (1991) demonstrated the reliability of 0.81 for permissive, 0.92 for authoritative, and 0.92 for authoritarian parenting style using test-retest method. The PSI was translated into Persian by Esfandiari (1995). Esfandiari (1995) found reliability estimates of $0.69,0.77$, and 0.73 for the permissive, authoritarian, and authoritative parenting styles, respectively. In the present study, the Cronbach alpha values of $0.89,0.91$, and 0.86 were reported for the permissive, authoritarian, and authoritative parenting styles, respectively.

\section{Results}

Demographic information is shown in Table 1.

Table 2 presents the descriptive statistics for parenting styles, emotion regulation strategies, and borderline personality traits.
Table 3 presents the correlation matrix between the study variables. Among the variables correlated with borderline personality traits, suppression and authoritarian parenting style had the highest correlations with borderline personality traits. Overall, all study variables were significantly correlated with borderline personality traits at the 0.01 and 0.05 significance levels.

The stepwise regression analysis was used to examine multiple correlations and determine the best predictors of borderline personality traits among parenting styles. As you can see in Table 4, in the first step, the authoritarian parenting style had a correlation of 0.47 with borderline personality traits and explained $22 \%$ of its variance at the 0.01 significance level (adjusted $\mathrm{R}^{2}=0.003, \mathrm{P}<0.01$ ). In the second step, authoritarian and authoritative parenting styles together had a correlation of 0.52 with borderline personality traits at the 0.01 significance level and explained $27 \%$ of the variance of borderline personality traits, and authoritative parenting style explained $26 \%$ of the variance of borderline personality traits (adjusted $\mathrm{R}^{2}$ $=0.265, \mathrm{P}<0.01)$. Among the three parenting styles, two styles of authoritarian and authoritative parenting styles were good predictors of borderline personality traits.

Table 1. Demographic information

\begin{tabular}{cccc}
\hline Participants & Gender & Age, $\mathbf{y}$ & N \\
\hline Students & Female & $14-16$ & 261 \\
Mothers & Female & $30-60$ & 261 \\
\hline & & & $\begin{array}{c}\text { PRACTICE in } \\
\text { CLINICAL PSYH }\end{array}$
\end{tabular}

Table 2. Descriptive statistics of the study variables

\begin{tabular}{lcc}
\hline \multicolumn{2}{c}{ Variables } & Mean \pm SD \\
\hline & Permissive parenting & $18.11 \pm 8.41$ \\
Parenting styles & Authoritarian parenting & $20.84 \pm 10.83$ \\
& Authoritative parenting & $22.04 \pm 8.02$ \\
Emotion regulation strategies & Reappraisal & $22.29 \pm 8.38$ \\
& Suppression & $15.77 \pm 5.81$ \\
Borderline personality traits & Hopelessness & $3.35 \pm 1.77$ \\
& Impulsivity & $4.50 \pm 2.06$ \\
& Dissociative symptoms & $1.91 \pm 1.41$ \\
\hline & Borderline traits total score & $9.77 \pm 4.55$ \\
\hline
\end{tabular}


Table 3. Correlation matrix between the study variables

\begin{tabular}{|c|c|c|c|c|c|c|c|c|c|c|}
\hline \multicolumn{11}{|c|}{ Correlations } \\
\hline 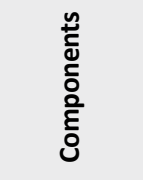 & 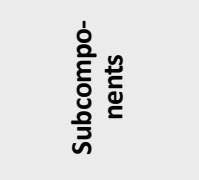 & 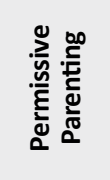 & 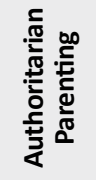 & 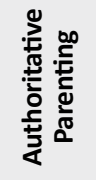 & 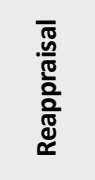 & $\begin{array}{l}\text { 흠 } \\
\text { ญे } \\
\text { 흠 } \\
\text { ज }\end{array}$ & 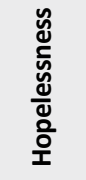 & 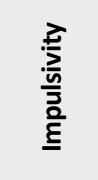 & 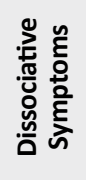 & 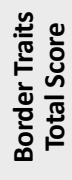 \\
\hline \multirow{3}{*}{$\begin{array}{l}\text { Parenting } \\
\text { styles }\end{array}$} & $\begin{array}{l}\text { Permissive } \\
\text { parenting }\end{array}$ & 1 & & & & & & & & \\
\hline & $\begin{array}{l}\text { Authoritarian } \\
\text { parenting }\end{array}$ & $-0.29 *$ & 1 & & & & & & & \\
\hline & $\begin{array}{l}\text { Authoritative } \\
\text { parenting }\end{array}$ & $-0.25^{*}$ & $-0.40^{*}$ & 1 & & & & & & \\
\hline \multirow{2}{*}{$\begin{array}{l}\text { Emotion } \\
\text { regulation } \\
\text { strategies }\end{array}$} & Reappraisal & $0.17^{*}$ & $-0.52^{*}$ & $0.36^{*}$ & 1 & & & & & \\
\hline & Suppression & -0.036 & $0.56^{*}$ & $-0.41^{*}$ & $-0.72^{*}$ & 1 & & & & \\
\hline \multirow{4}{*}{$\begin{array}{l}\text { Borderline } \\
\text { personality } \\
\text { traits }\end{array}$} & Hopelessness & $-0.13^{* *}$ & $0.41^{*}$ & $-0.29 *$ & $-0.49 *$ & $0.54^{*}$ & 1 & & & \\
\hline & Impulsivity & $-0.13^{* *}$ & $0.46^{*}$ & $-0.34^{*}$ & $-0.53^{*}$ & $0.53^{*}$ & $0.63^{*}$ & 1 & & \\
\hline & $\begin{array}{l}\text { Dissociative } \\
\text { symptoms }\end{array}$ & -0.039 & $0.34^{*}$ & $-0.35^{*}$ & $-0.44^{*}$ & $0.50^{*}$ & $0.54^{*}$ & $-0.68^{*}$ & 1 & \\
\hline & $\begin{array}{l}\text { Borderline per- } \\
\text { sonality traits } \\
\text { total score }\end{array}$ & $-0.12^{*}$ & $0.47^{*}$ & $-0.38^{*}$ & $-0.57^{*}$ & $0.60^{*}$ & $0.84^{*}$ & $0.91^{*}$ & $0.83^{*}$ & 1 \\
\hline
\end{tabular}

$* \mathrm{P}<0.05 ; * * \mathrm{P}<0.01$

Table 4. Model summary of parenting styles predicting personality traits

\begin{tabular}{cccccr}
\hline Model & $\mathbf{R}$ & $\mathbf{R}^{2}$ & Adjusted $\mathbf{R}^{2}$ & $\mathbf{F}$ & Sig. \\
\hline 1 & 0.476 & 0.226 & 0.223 & 75.80 & 0.0001 \\
2 & 0.520 & 0.270 & 0.265 & 47.77 & 0.0001 \\
\hline & & & & PLANICA In PSYCH $\odot$ LOGY \\
\hline
\end{tabular}

Table 5. Model summary for emotion regulation strategies predicting borderline personality traits

\begin{tabular}{cccccc}
\hline Model & R & $\mathbf{R}^{2}$ & Adjusted $\mathbf{R}^{2}$ & F & Sig. \\
\hline 1 (Suppression) & 0.609 & 0.371 & 0.368 & 152.53 & 0.0001 \\
2 (Reappraisal) & 0.638 & 0.407 & 0.402 & 88.47 & 0.0001 \\
\hline
\end{tabular}

Authoritarian parenting style 2. Authoritarian parenting style, authoritative parenting style

The stepwise regression analysis was used to examine the predictability of borderline personality traits based on emotion regulation strategies. As it is shown in Table 5 , in the first step, suppression had a correlation of 0.60 with borderline personality traits and explained $36 \%$ of its variance at the 0.01 significance level (adjusted $\mathrm{R}^{2}$ $=0.368, \mathrm{P}<0.01)$. In the second step, suppression and reappraisal together had a correlation of 0.63 with borderline personality traits and explained $40 \%$ of its variance at the 0.01 significance level (adjusted $R^{2}=0.402$, 
$\mathrm{P}<0.01)$. Both emotion regulation strategies had a significant role in predicting borderline personality traits.

\section{Discussion}

Based on the study results, among the three parenting styles, authoritarian and authoritative styles significantly predicted borderline personality traits. This finding is consistent with the findings of Khanjani, Hashemi, and Elhamfar (2011); Sajjadi, Sarabian, \& Sharifi (2013); and Shafipour, Sheikhi, Mirzaei, \& Kazemnezhad Leili (2015), regarding the relationship between parenting styles and psychological and behavioral problems. Although there is a consensus that emotion dysregulation is the main characteristic of BPD, the exact cause of the disorder is not known. Previous studies on the causes of BPD have largely focused on genetic and biological factors; however, the role of environmental and family factors, especially parenting styles, cannot be denied.

A warm and friendly relationship between adolescents and parents provide a healthy condition for the development of the youth. Adolescents in accepted and loved families express good maturity traits, cheerfulness, and positive emotions (Okorodudu, 2010). Children raised by authoritarian parents are seemingly unhappy, anxious, moody, insecure, and almost aimless. Children of permissive parents tended to be aggressive, aimless, often impulsive, without self-control and low in achievement and independence (Pearson, 2013). Authoritarian parents emphasize control and obedience, enforce discipline via punishment, and expect children to obey their orders without arguing (Baumrind, 1971). It seems that when children are subjected to this kind of parenting style, they are more likely to become anxious, isolated, and dissatisfied, and this treatment makes them more vulnerable to mental disorders (Alexander, 2006). In addition, parents' criticism of their children's emotional expression is one of the most important factors that can make children prone to borderline personality traits, because when any emotional expression from the child receives negative feedback from parents, the child becomes vulnerable to emotional instability and inability to control impulses, and these are among the main features of borderline personality (Hooly, 2007).

According to the study results, the permissive parenting style was not a significant predictor of borderline personality traits. Parents with a permissive parenting style do not control their children, do not expect them to behave rationally, and do not teach them how to be independent and self-confident (Skodol et al., 2002). This parenting style is characterized by a high level of responsiveness along with a low level of expectation and has the lowest level of structure. The element of care is also low in this kind of parenting; therefore, the permissive parenting style is also expected to be related to negative consequences and various mental problems in children (Aunola \& Nurmi, 2005).

The study results also indicated that both emotion regulation strategies of reappraisal and suppression were significant predictors of borderline personality and its components. This finding is in line with the results of Bashrpoor, Toloi Mehmandoost Olya, Narimani, and Atadokht (2014) and Sajadi, Arshadi, Zargar, Mehrabizade Honarmand, and Hajjari (2015). Emotion regulation strategies are an effective way to change emotions, feelings, desires, beliefs, and practices of the individual and giving order and meaning to daily life so that one can reach higher goals; people's success in reaching goals is determined according to their skills in emotion regulation, knowledge, and behavior (Jazaieri, McGonigal, Jinpa, Doty, Gross, \& Goldin, 2014). Emotion regulation is an important feature of BPD (Lotfi et al., 2018). The American Psychiatric Association (2013) considers emotional instability as a symptom of a borderline personality because of the reactive nature of the mood, which usually lasts for several hours and rarely for several days. Thus, there is a relationship between emotional states (such as irritability or anxiety) with borderline personality, and variables such as emotional processing and emotion regulation play a mediating role in this regard.

The study findings can be explained by the following points. BPD patients' inability to assimilate positive and negative aspects of life, makes their emotional experiences incongruous and experiencing incongruous emotions can lead to anger, impulsivity, and impairment in everyday functioning. The lack of control over emotions that may result from the inability to recognizing them may lead to impulsive behaviors, mood swings, intense need to control, and other symptoms of BPD. Patients with BPD tend to have many intruding thoughts that may lead to long-term or strict use of inhibition by the patients. This process in turn can prevent personality reorganization and stability.

According to the literature, there is a negative association between reappraisal and borderline personality traits, and this emotion regulation strategy can predict borderline personality traits. Gardner, Qualter, and Tremblay (2010) found that emotional management and emotional awareness negatively predicted borderline personality symptoms. This fact can explain patients' difficulty in using reappraisal in social situations. Using this emotion regulation strategy when faced with stressful events, 
the person engages in thinking about enjoyable things instead of the actual event, the positive aspects of the event, personal growth, or the best way to overcome the negative event or change it. These processes are accompanied by a reduction in borderline symptoms and behaviors. Given the essential role of emotion regulation in interpersonal relationships, the transference of feelings to others, and creating, keeping, and cutting relationships (Gross, 2001), reappraisal, as an emotion regulation strategy, can explain BPD patients' difficulties in everyday activities, including career activities and social and family relationships. On the other hand, emotion regulation strategies have their roots in social, cognitive, and emotional development, and dysfunction in reappraisal can influence the formation and persistence of emotional and personality problems (Gross, 2001), including BPD.

The study results also indicated that suppression could predict borderline personality traits, and there was a direct relationship between the two variables. Because of the inability to internalize unpleasant events, BPD patients tend to use a dissociative processing style. As BPD people usually experience different and often paradoxical emotions, they are more likely to experience incongruent emotions. These patients try to suppress the negative and unbearable aspects of their personality, or project them to others, but, due to their impulsivity, they finally find most of their own emotions uncontrollable, and this is reflected in the unpredictability of their behaviors.

As a result, the more a person uses suppression as an emotion regulation strategy, the more likely they are to experience impulsivity, mood swings, and an intense need to control emotions that are all symptoms of BPD.

The present study had some limitations, including the lack of male students in the sample that limits the generalizability of the data, and the use of a self-report instrument, subject to self-report biases. Similar studies need to be done with male students from different cultures to improve the generalizability of the results. We also suggest that comparative effectiveness research studies should be conducted to identify the best interventions for BPD patients.

Finally, based on the results of this research, parenting management training for parents and emotion regulation training for adolescents are important shielding factors for preventing borderline personality traits.

\section{Conclusion}

Overall, the present study helps us understand parenting styles and emotion regulation strategies and predict borderline personality traits in adolescences. Also, findings show that the relationships between borderline personality traits, parenting styles, and emotion regulation strategies on Iranian samples are the same as other cultures.

\section{Ethical Considerations}

\section{Compliance with ethical guidelines}

All ethical principles were considered in this research. Informed consent was obtained from all study participants; they were also assured about the confidentiality of their information. Moreover, they were allowed to discontinue.

\section{Funding}

This research did not receive any grant from funding agencies in the public, commercial, or non-profit sectors.

\section{Authors' contributions}

All authors were equally contributed in preparing this article.

\section{Conflict of interest}

The authors declared no conflict of interest.

\section{References}

Alexander, T. E. (2006). Parenting and behaviors of 12 to 15 year old males in The Virgin Islands [PhD. thesis]. Minneapolis, MN: Walden University. https://search.proquest.com/openview/249 5e9b9660e6c79432a927c4d0a1450/1?pq-origsite=gscholar\&c $\mathrm{bl}=18750 \&$ diss $=y$

Aliloo, M., Khanjani, Z., \& Bayat, A.(2017). Prediction of emotional disorders related to adolescent anxiety based on emotion regulation coping strategies and borderline personality disorder traits. Clinical Psychology Studies, 25(7),108-28.

Aunola, K., \& Nurmi, J. E. (2005). The role of parenting styles in children's problem behavior. Child development, 76(6), 1144-59.

American Psychiatric Association. (2013). Diagnostic and Statistical Manual of Mental Disorders (DSM-5). Washington, D.C: American Psychiatric Publishing. [DOI:10.1176/appi. books.9780890425596]

Baglivio, M. T., Epps, N., Swartz, K., Huq, M. S., Sheer, A., \& Hardt N. S. (2014). The prevalence of Adverse Childhood Experiences (ACE) in the lives of juvenile offenders. Journal of Juvenile Justice, 
$3(2), \quad 1 . \quad$ https://www.prisonpolicy.org/scans/Prevalence_of_ ACE.pdf

Balzarotti, S., John, O. P., \& Gross, J. J. (2010). An Italian adaptation of the emotion regulation questionnaire. European Journal of Psychological Assessment, 26(1), 61-7. [DOI:10.1027/1015-5759/a000009]

Bashrpoor, S., Toloi Mehmandoost Olya, A., Narimani, M., \& Atadokht, A. (2014). [Relation of emotion processing styles and alexithymia with symptoms of borderline personality disorder (Persian)]. Journal of Babol University of Medical Sciences, 16(7), 55-62. http://jbums.org/article-1-4830-en.html

Baumrind, D. (1971). Current patterns of parental authority. Developmental Psychology, 4(1, Pt.2), 1-103. [DOI:10.1037/h0030372]

Besharat, M. A., Hooshmand, S. N., Rezazadeh, S. M. R., \& Gholamali Lavasani, M. (2015). [The moderating role of basic psychological needs satisfaction on the relationship between parenting styles and children's marital satisfaction (Persian)]. Journal of Family Psychology, 2(1), 15-28. http://iifp.ir/article-1-63-en. html

Brüne, M., Walden, S., Edel, M. A., \& Dimaggio, G. (2016). Mentalization of complex emotions in borderline personality disorder: The impact of parenting and exposure to trauma on the performance in a novel cartoon-based task. Comprehensive Psychiatry, 64, 29-37. [DOI:10.1016/j.comppsych.2015.08.003] [PMID]

Buri, J. R. (1991). Parental authority questionnaire. Journal of Personality Assessment, 57(1), 110-9. [DOI:10.1207/s15327752jpa5701_13] [PMID]

Claridge, G., \& Broks, P. (1984). Schizotypy and hemisphere function-I: Theoretical considerations and the measurement of schizotypy. Personality and Individual Differences, 5(6), 633-48. [DOI:10.1016/0191-8869(84)90111-9]

Esfandiari, GH. (1995). [Examination of parenting styles in mothers of children with behavioral problems and mothers of normal children, and investigation of the effectiveness of mothers' training on children's behavioral problems (Persian) ] [Master's thesis]. Tehran: Tehran Psychiatric Institute.

Fletcher, K., Parker, G., Bayes, A., Paterson, A., \& McClure, G. (2014). Emotion regulation strategies in bipolar II disorder and borderline personality disorder: Differences and relationships with perceived parental style. Journal of Affective Disorders, 157, 52-9. [DOI:10.1016/j.jad.2014.01.001] [PMID]

Gardner, K. J., Qualter, P., \& Tremblay, R. (2010). Emotional functioning of individuals with borderline personality traits in a nonclinical population. Psychiatry Research, 176(2-3), 208-12. [DOI:10.1016/j.psychres.2009.08.001] [PMID]

Gross, J. J. (2001). Emotion regulation in adulthood: Timing is everything. Current Directions in Psychological Science, 10(6), 214-9. [DOI:10.1111/1467-8721.00152]

Gross, J. J., \& John, O. P. (2003). Individual differences in two emotion regulation processes: Implications for affect, relationships, and well-being. Journal of Personality and Social Psychology, 85(2), 348-62. [DOI:10.1037/0022-3514.85.2.348] [PMID]

Heaven, P. C. L., Mak, A., Barry, J., \& Ciarrochi, J. (2002). Personality and family influences on adolescent attitudes to school and self-rated academic performance. Personality and Individual Differences, 32(3), 453-62. [DOI:10.1016/S0191-8869(01)00041-1]
Hooley, J. M. (2007). Expressed emotion and relapse of psychopathology. Annual Review of Clinical Psychology, 3, 329-52. [DOI:10.1146/annurev.clinpsy.2.022305.095236] [PMID]

Hutsebaut, J., Feenstra, D. J., \& Kamphuis, J. H. (2016). Development and preliminary psychometric evaluation of a brief self-report questionnaire for the assessment of the DSM-5 level of personality functioning scale: The LPFS Brief Form (LPFS-BF). Personality Disorders: Theory, Research, and Treatment, 7(2), 192-7. [DOI:10.1037/per0000159] [PMID]

Hutsebaut, J., Kamphuis, J. H., Feenstra, D. J., Weekers, L. C., \& De Saeger, H. (2017). Assessing DSM-5-oriented level of personality functioning: Development and psychometric evaluation of the Semi-Structured Interview for Personality Functioning DSM-5 (STiP-5.1). Personality Disorders: Theory, Research, and Treatment, 8(1), 94-101. [DOI:10.1037/per0000197] [PMID]

Jansen, E., Daniels, L. A., \& Nicholson, J. M. (2012). The dynamics of parenting and early feeding-constructs and controversies: A viewpoint. Early Child Development and Care, 182(8), 967-81. [DO: 10.1080/03004430.2012.678593]

Jazaieri, H., McGonigal, K., Jinpa, T., Doty, J. R., Gross, J. J., \& Goldin, P. R. (2014). A randomized controlled trial of compassion cultivation training: Effects on mindfulness, affect, and emotion regulation. Motivation and Emotion, 38(1), 23-35. [DOI:10.1007/s11031-013-9368-z]

Judd, P. H., McGlashan, T.H. (2003). A developmental model of borderline personality disorder: Understanding variations in course and outcome. Washington: American Psychiatric Publishing.

Kashdan, T. B., Barrios, V., Forsyth, J. P., \& Steger, M. F. (2006). Experiential avoidance as a generalized psychological vulnerability: Comparisons with coping and emotion regulation strategies. Behavior Research and Therapy, 44(9), 1301-20. [DOI:10.1016/j.brat.2005.10.003] [PMID]

Khanjani, Z., Hashemi, T., \& Elhamfar, F. (2011). [A study of relationship between parental rearing methods and attachmen styles with depression symptoms in adolescents (Persian)]. Journal of Instruction and Evaluation, 4(14), 91-106. http://jinev. iaut.ac.ir/article_521549.html

Lotfi, M., Amini, M., Fathi, A., Karami, A., \& Ghiasi, S. (2014). Personality traits, emotion regulation and impulsive behaviors in patients with borderline personality disorder. Practice in Clinical Psychology, 2(1), 27-33. http://jpcp.uswr.ac.ir/article-1-161-en.html

Lotfi, M., Amini, M., Fathi, A., Karami, A., Ghiasi, S., \& Sadeghi, Sh. (2018). Cognitive emotion regulation strategies in prisoners with borderline personality disorder. Practice in Clinical Psychology, 6(3), 153-8. http://jpcp.uswr.ac.ir/article-1-530-en.html

Lyons-Ruth, K., Choi-Kain, L., Pechtel, P., Bertha, E., \& Gunderson, J. (2011). Perceived parental protection and cortisol responses among young females with borderline personality disorder and controls. Psychiatry Research, 189(3), 426-32. [DOI:10.1016/j.psychres.2011.07.038] [PMID]

Mahmoud Alilou, M., Khanjani, Z., \& Bayat, A. (2017). [Prediction of anxiety-related emotional disorders in adolescences based on emotion regulation, coping strategies and symptoms borderline personality disorder (Persian)]. Clinical Psychology Studies, 7(25), 107-28. http://jcps.atu.ac.ir/article_7134.html

Millon, T., Millon, C. M., Meagher, S. E., Grossman, S. D., \& Ramnath, R. (2004). Personality disorders in modern life. Hoboken, NJ: John Wiley \& Sons, Inc. https:/ / books.google.com/ books?id=QPa1NAEACAAJ\&dq 
Mohammadzadeh, A., Goodarzi, M. A., Taghavi, S. M. R., \& Mollazadeh, J. (2006). [The study of factor structure, validity, reliability and standardization of borderline personality scale (STB) in Shiraz University students (Persian)]. Journal of Fundamentals of Mental Health, 7(28), 75-89. [DOI:10.22038/ JFMH.2005.1842]

Morey, L. C. (2018). Application of the DSM-5 level of personality functioning scale by lay raters. Journal of Personality Disorders, 32(5):709-20. [DOI:10.1521/pedi_2017_31_305] [PMID]

Okorodudu, G. N. (2010). Influence of parenting styles on adolescent delinquency in Delta Central Senatorial District. Edo Journal of Counselling, 3(1), 58-86. [DOI:10.4314/ejc.v3i1.52682]

Olivari, M. G., Cuccì, G., Bonanomi, A., Tagliabue, S., \& Confalonieri, E. (2018). Retrospective paternal and maternal parenting styles, regulatory self-efficacy and adolescent risk taking. Marriage \& Family Review, 54(3), 282-95. [DOI:10.1080/014949 29.2017.1403990]

Pearson, A. L. (2013). The impact of parenting styles on the emotional regulation of adolescents. Master of Social Work Clinical Research Papers, 248. http://sophia.stkate.edu/msw_papers $/ 248$

Rawlings, D., Claridge, G., \& Freeman, J. L. (2001). Principal components analysis of the schizotypal personality scale (STA) and the borderline personality scale (STB). Personality and Individual Differences, 31(3), 409-19. [DOI:10.1016/S01918869(00)00146-X]

Sadock, B. J., Kaplan, H. I., \& Sadock, V. A. (2015). Kaplan \& Sadock's synopsis of psychiatry: Behavioral sciences/clinical psychiatry. Philadelphia, PA: Lippincott Williams \& Wilkins.

Sajadi, S. F., Arshadi, N., Zargar, Y., Mehrabizade Honarmand, M., \& Hajjari, Z. (2015). Borderline personality features in students: The predicting role of schema, emotion regulation, dissociative experience and suicidal ideation. International Journal of High Risk Behaviors and Addiction, 4(2), e20021. [DOI:10.5812/ijhrba.20021v2] [PMID] [PMCID]

Sajjadi, M., Sarabian, S., Sharifi Daramadi, P. (2014). [Comparison of teen aggression level based on parenting styles and parentchild attachment styles (Persian)]. Journal of Medical Council of Iran, 31(4), 298-306. http:/ /jmciri.ir/article-1-1677-fa.html

Sansone, R, A., Farukhi, Sh., \& Wiederman, M. W. (2013). Perceptions of childhood caretakers and borderline personality symptomatology. Child Abuse \& Neglect, 37(11), 1030-3. [DOI:10.1016/j.chiabu.2013.06.008] [PMID]

Shafipour, S. Z., Sheikhi, A., Mirzaei, M., Kazemnezhad Leili, E. (2015). [Parenting styles and its relation with children behavioral problems (Persian)]. Journal of Holistic Nursing and Midwifery, 25(2), 49-56. http://hnmj.gums.ac.ir/article-1-459-en.html

Shankar, R. (1998). Borderline personality disorder and the psychosis spectrum: A personality and divided visual field study $[\mathrm{PhD}$. Dissertation]. Oxford, UK: University of Oxford. http://www. opengrey.eu/item/display/10068/614537

Skodol, A. E., Clark, L. A., Bender, D. S., Krueger, R. F., Morey, L. C., Verheul, R., et al. (2011). Proposed changes in personality and personality disorder assessment and diagnosis for DSM-5 Part I: Description and rationale. Personality Disorders: Theory, Research, and Treatment, 2(1), 4-22. [DOI:10.1037/ a0021891]
Skodol, A. E., Gunderson, J. G., Pfohl, B., Widiger, T. A., John Livesley, W., \& Siever, L. J. (2002). The borderline diagnosis I: Psychopathology, comorbidity, and personality structure. Biological Psychiatry, 51(12), 936-50. [DOI:10.1016/S00063223(02)01324-0]

Torgersen, S., Kringlen, E., \& Cramer, V. (2001). The prevalence of personality disorders in a community sample Archives of General Psychiatry, 58(6), 590-6. [DOI:10.1001/ archpsyc.58.6.590] [PMID]

Underwood, L. A., Washington, A. (2016). Mental illness and juvenile offenders. International Journal of Environmental Research and Public Health, 13(2), 228. [DOI:10.3390/ijerph13020228] [PMID] [PMCID]

Warren, R. (2015). Emotion regulation in borderline personality disorder: The role of self-criticism, shame, and self-compassion. Personality and Mental Health, 9(1), 84-6. [DOI:10.1002/ pmh.1290] [PMID]

Wojciechowski, T. W. (2018). Developmental trajectories of cocaine/crack use among juvenile offenders: PTSD as a risk factor. Journal of Drug Issues, 48(1), 50-66. [DOI:10.1177/0022042617729352] 